\title{
Os filmes verbais de Erico Verissimo: uma abordagem cinematográfica e literária de Olhai os Lírios do Campo em Solo de Clarineta
}

\author{
The verbal films of Erico Verissimo: a cinematographic and literary approach to Olhai os Lírios do Campo in \\ Solo de Clarineta
}

\section{Márcio Soares dos Santos}

Universidade Federal do Rio Grande do Sul - UFRGS - Porto Alegre - Rio Grande do Sul - Brasil

\begin{abstract}
Resumo: O artigo identifica no livro de memórias do autor Erico Verissimo, Solo de Clarineta I, sua formação cinematográfica. Aproxima esses elementos da memória ao conteúdo literário e adaptado para o cinema em Olhai os Lírios do Campo, o mais vendido do autor. O processo relaciona as obras, ressignifica a história e a ficção. A metodologia é através do processo comparativo entre obras. O embasamento teórico encontra-se no estudo da cultura russa de luri Lótman, com base em sua teoria da cadeia de signos organizados. Resgatamos o romance na sua totalidade, estruturado por meio da técnica de intercalação temporal, o que permite análise literária e cinematográfica. Buscamos os códigos da história do cinema da época de lançamento, para identificar as representações de nosso objeto e elucidar a obra do autor. Buscamos referências cinematográficas e memórias do livro Olhai os Lírios do Campo em Solo de Clarineta I, enfatizamos trechos concorrentes para o entendimento do processo de criação do romance. Nessa linha de pensamento, descobrimos nele as nuances da montagem, sua origem em outras artes e as semelhanças estruturais entre literatura e cinema.
\end{abstract}

Palavras-chave: literatura, cinema, Erico Veríssimo, biografia, representações.

Resumen: El artículo identifica en el libro de memorias del autor Erico Verissimo, Solo de Clarineta I, su formación cinematográfica. Aproxima esos elementos de la memoria al contenido literario y adaptado para el cine en Mira los Lirios del Campo (1938), el más vendido del autor. El proceso relaciona las obras, resignifica la historia y la ficción. La metodología es a través del proceso comparativo entre obras. El fundamento teórico se encuentra en el estudio de la cultura rusa de luri Lótman, con base en su teoría de la cadena de signos organizados. Rescatamos la novela en su totalidad, estructurado por medio de la técnica de intercalación temporal, lo que permite análisis literario y cinematográfico. Buscamos los códigos de la historia del cine de la época de lanzamiento, para identificar las representaciones de nuestro objeto y elucidar la obra del autor. Buscamos referencias cinematográficas y memorias del libro Mirad los Lirios del Campo en Solo de Clarineta I, enfatizamos fragmentos concurrentes para el entendimiento del proceso de creación de la novela. En esa línea de pensamiento, descubrimos en él los matices del montaje, su origen en otras artes y las semejanzas estructurales entre literatura y cine.

Palabras Claves: literatura, cine, Erico Verissimo, biografía, representaciones. 


\section{Introdução}

O escritor brasileiro Erico Verissimo, expoente da moderna literatura brasileira, mesmo elegendo a música como sua segunda predileção artística, sofreu forte influência da "sétima arte". Em sua obra memorialista, Solo de Clarineta ${ }^{1}$, encontramos sua formação fílmica e concomitantemente um breve panorama do tempo de escrita e da publicação da obra Olhai os Lírios do Campo.

A nossa pesquisa de doutorado $A$ adaptação de Olhai os Lírios do Campo para o cinema argentino tem o apoio do Museu do Cinema de Buenos Aires e da Universidade de Buenos Aires (UBA). O Museu preserva o roteiro do filme, ao qual obtivemos acesso. O museu também preserva dezenas de reportagens do período de lançamento da obra cinematográfica nos Estados Unidos, na Argentina e no Brasil. A Universidade daquele país demonstra interesse em colaborar com a pesquisa, através de um núcleo consistente de estudos que abrange literatura e cinema. A origem de nosso trabalho aconteceu durante a significativa busca pela cópia do filme, encontrado, somente em formato DVD, em uma loja de filmes argentinos antigos -localizada na região central de Buenos Aires. Existe a possibilidade de nosso retorno à capital da Argentina, pretendemos manter vínculos para tratar de literatura e cinema com a Universidade, o Museu e outras instituições com informações e interesses na obra de Erico Verissimo.

Aproximando as duas artes, cinema e literatura, podemos investigar as frequentes memórias cinematográficas de Solo de Clarineta, narrativa autobiográfica na qual Erico relata sua vida e obra até a década de 1950 e que foi seu último trabalho publicado.

\footnotetext{
${ }^{1}$ Volumes I e II - O primeiro livro autobiográfico de Verissimo foi publicado em 1973 e narra da infância do escritor até o pedido de casamento à filha Clarissa. A continuação segue da vida do romancista, com registros de viagens pelos Estados Unidos e pela Europa. A obra ficou Inacabada,com o falecimento do autor, sendo sua parte final organizada por Flávio Loureiro Chaves. Cumpre observar, também, que Solo de Clarineta representou uma ampliação de um primeiro esboço autobiográfico, O Escritor Diante do Espelho, publicado em 1967, no terceiro volume na edição de sua Ficção Completa pela Aguilar.
}

O primeiro filme de Erico levado às salas de cinema acontece no país vizinho, Argentina, em 1947, pelas mãos do diretor Ernesto Arancibia, recebendo o nome de Miradlos Lírios del Campo. O escritor esteve em Buenos Aires para a leitura do roteiro de Tulio Demicheli e Mariano Perla e também marcou presença no lançamento da película em Porto Alegre $^{2}$. Ressalte-se, porém, que em suas memórias, ao se referir aos fatos da negociação dos direitos cinematográficos do romance, caracteriza a transação com a expressão "apreço de banana". Esse episódio da sua história, Verissimo não pretendia contar. A adaptação, porém, foi extremamente fiel ao livro e difundiu o romance no sul da América Latina.

Em termos de tempo e espaço, essa obra literária, a mais vendida do romancista, ${ }^{3}$ pode ser imaginada como o "plot point" de sua carreira de escritor. O termo, oriundo da indústria cinematográfica, designa o ponto de virada no roteiro de uma narrativa de cinema. Como podemos observar em trechos de Solo de Clarineta, omodo devida do escritor nunca mais foi o mesmo depois do romance de Eugenio e Olivia. Disse Verissimo: "do ponto de vista de vendas, foi decisivo na minha carreira de escritor" (1974, p. 267).

Ao examinar a trajetória de Olhai os Lírios do Campo, podemos dizer que o início do processo em torno da validade da obra decorre mais de uma questão de perspectiva literária do que da sua popularidade. Foi uma narrativa amorosa que Erico quis contar. A valorização temática da história variou de acordo com as perspectivas dos leitores e dos críticos, favoráveis ou não a esse gênero de romance, assim como ocorre em qualquer outro meio de difusão.

Em Olhai os Lírios do Campo, considerado o "divisor de águas" de sua carreira, o autor se empenhava em descobrir novas dimensões para o romance urbano, enquanto a literatura de sua

\footnotetext{
2 Informação obtida por trocas de e-mails em 15 de maio de 2015 com Luis Fernando Verissimo, filho do escritor, que comenta, também, ter estado presente nesta sessão com a presença de diretor, atores e produtores da obra fílmica.

Segundo dados obtidos junto a sua editora, a Companhia das Letras.
} 
geração, nos anos 30 , se voltava para o regional, se especializava em conflitos do interior brasileiro, revelados na ficção de Graciliano Ramos, José Lins do Rego, Jorge Amado. Da sua maneira, Erico redescobria o Brasil, apresentava o sentido urbano da Porto Alegre naquela década, criando personagens deslocados na cidade, ainda com hábitos do interior.

Olhai os Lírios do Campo pode ser considerado, deste modo, um documento da vida na capital do Rio Grande do Sul, pensado por um romancista que talvez não quisesse produzir personagens com alta densidade dramática, pois, como afirmava ele, não se considerava mais do que "um contador de histórias".

Do ponto de vista estrutural, e aqui podemos fazer a comparação com o "fazer cinema", o escritor incluiu na ficção brasileira uma de suas preocupações válidas de narrador: a justaposição do tempo e do espaço. Importa observar que os dramas se constroem com memória e imaginação, sem a preocupação de firmar conceitos, mas de narrar ou encontrar a melhor maneira de contar uma história.

O flashback protagoniza, também, a adaptação de Olhai os Lírios do Campo. Nesta obra, filmada em preto e branco, encontramos uma produção moderna para o cinema da década de 1940. Os mecanismos técnicos auxiliam a retratação da passagem de tempo. Em um trajeto de viagem do protagonista Eugenio Fontes, as histórias do passado se intercalam com as do presente em uma sucessão de pausas focadas no rosto do médico protagonista narrador:

Figura 1: Frame de cena do filme Mirad los Lírios del Campo

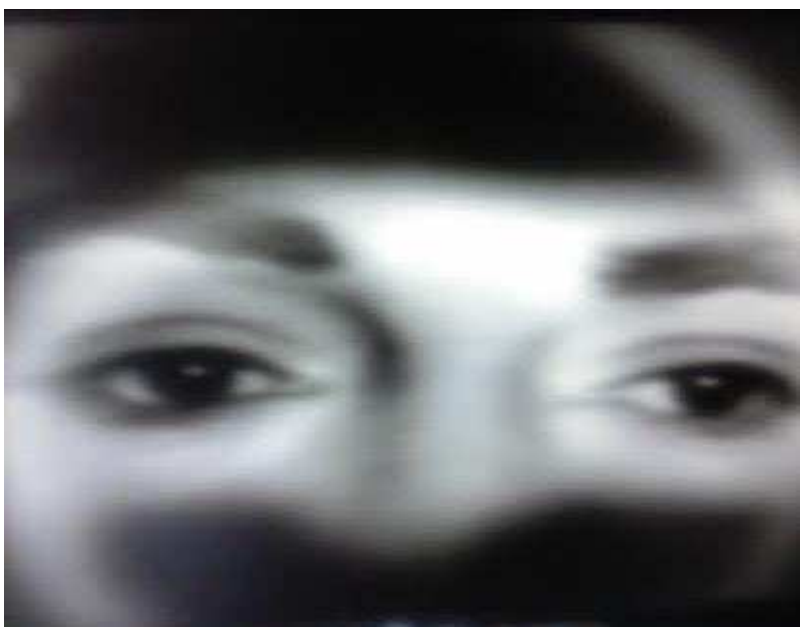

Fonte: Filme Mirad los Lírios del Campo. Argentina, 1947. Direção: Ernesto Arancibia.

De acordo com Lótman (1978), no cinema a unidade da divisão da sequência é muito facilmente posta em evidência. A narração cinematográfica pode ser examinada por uma série de sequências associadas por acumulação. O romance Olhai os Lírios do Campo foi, na sua totalidade, estruturado por meio da técnica de intercalação temporal. A obra compreende uma alternação do tempo presente com uma soma de cortes que indicam o passado das personagens. A técnica auxilia na organização das histórias contadas por Erico Verissimo:

Cada um dos elementos da estrutura artística existe enquanto possibilidade na estrutura da linguagem e - de modo mais lato - na estrutura da consciência do homem. É por isso que a história da evolução artística da humanidade pode ser descrita relativamente a qualquer um dos dois, quer seja a história deste ou daquele gênero. (LOTMAN, 1978, p. 427).

\section{0 plot point da literatura de Verissimo}

A busca pela estabilidade financeira caracterizou parte da vida do escritor brasileiro. Já adulto, no início da década de 1930, partia de Cruz Alta para Porto Alegre com ajuda do sogro e prazo de validade para deslanchar na carreira de Letras. Acompanhado de sua esposa Mafalda hospedou-se em pensões e lugares pequenos. Em 1935, visitou o Rio de Janeiro pela primeira vez e conheceu pessoalmente grandes nomes da literatura: Ernani Fornari, Jorge Amado, José Lins do Rego, Carlos Drummond de Andrade, Graciliano Ramos, entre outros. No mesmo ano nasceu sua primeira filha Clarissa, e publicou Caminhos Cruzados e Música ao Longe.

Em 1936 viveu dois novos acontecimentos: o nascimento do filho Luis Fernando Verissimo e publicação de mais um romance, Um Lugar ao Sol, cujo tema remetia ao que Mafalda e Erico experimentavam enquanto adultos jovens na luta pela sobrevivência.

Em 1937 Getúlio Vargas instituiu o Estado Novo e o Departamento de Imprensa e Propaganda (DIP) começou a exercer rigorosa censura sobre os 
meios de comunicação da época: rádios, jornais impressos, livros.

Naquele período de vida, para complementar o ordenado insuficiente da Livraria do Globo, onde Erico então trabalhava como conselheiro literário, também atuou como tradutor de livros do inglês para o português. Nessa fase Mafalda o acompanhava nas salas de cinema. Uma noite Erico a levou para que visse pela primeira vez um filme sonoro. Era $O$ Grande Gabo, com o ator austríaco Erich Von Strohein.

O casal gostava de mudar de casa, como se fosse um hábito simplesmente para variar de paisagem e vizinhança. Em setembro de 1937, instalaram-se numa casa da Rua Quintino Bocaiúva, no bairro Moinhos de Vento, em Porto Alegre. Nessa residência o escritor começou a escrever Olhai os Lírios do Campo. Na época, Erico não andava satisfeito com o que havia escrito e publicado. Foi quando fez uma visita ao hospital onde um amigo havia sido internado. O escritor encontrou naquele cenário um homem jovem saindo de um quarto com um bebê recém-nascido nos braços. Contaram a ele que a mãe havia morrido ao dar à luz a criança.

De acordo com o autor, a história reverberava em sua cabeça, provocando ideias, imagens, como a do o hospital, a dos médicos, a da mulher que morre e do homem que fica, e que provavelmente a amava. Diante disso, o escritor descobre que estava no caminho de um romance. O universo de Olhai os Lírios do Campo estava definido. Conforme relato autobiográfico, aquilo the provocara uma espécie de "exaltação interior (o exterior como de costume era de apatia crepuscular)" (1974, p.265). Verissimo conta ter tido vislumbres do passado em cada um dos personagens.

Semanas após esse acontecimento, conversou com o escritor João Santana à mesa de um café, no centro de Porto Alegre. $\mathrm{Na}$ ocasião, o amigo comentava a fúria aquisitiva do homem daquela época, sua sede de sucesso, em uma civilização de coisas em que os valores éticos eram cada vez mais levados em consideração.
Durante essa conversa, Erico desenhava a lápis no mármore da mesa. E sem se dar conta, havia já escrito sobre a pedra as seguintes palavras bíblicas: "Considerai os lírios do campo". $\mathrm{Na}$ oportunidade comentou se tratar de um bom título para um romance, mas não gostava da palavra "considerai". Mudou para "olhai". E definiu o título do livro.

Nesse dia, Erico também declarou que a profissão das personagens seria a Medicina. Criou o episódio da formatura, imaginou o evento no Theatro São Pedro, localizado na região central da capital gaúcha. Segundo o escritor, era uma noite quente de dezembro. "O perfume dos jasmins da minha infância foi convocado para embalsamar essa noite assinalada na vida de Olivia e Eugênio" (1974, p. 266).

Buscou na imaginação a fisionomia de Olivia e já no dia seguinte começou o primeiro capítulo da obra. O autor descreve a dúvida em começar pela formatura ou pelo hospital. Optou pelo último local, onde Olivia se encontra gravemente enferma. Erico ressalta que Eugenio já está casado com a outra personagem, a rica. Em relação à estrutura da narrativa, não tem dúvidas de que a história deve ser contada em flashbacks, com saltos ao passado.

Conta que, com os filhos pequenos em sua volta, não havia a paz necessária para escrever um livro. Foi quando decidiu se mudar para a Livraria do Globo, onde trabalhava. Pediu ao livreiro Henrique Bertaso que lhe concedesse um espaço: uma espécie de passarela que atravessava de lado a lado o enorme salão da tipografia, onde estavam instaladas as linotipos. Conforme relato do escritor, o lugar era quente e abafado, especialmente no verão. Subia de baixo um bafo quente de chumbo derretido, além de uma poeira negra. Foi nessa "sucursal do inferno" que Erico Verissimo escreveu boa parte de Olhai os Lírios do Campo.

Publicado em 1938, teve logo uma surpreendente aceitação popular. Bertaso, na oportunidade, não acreditava que um escritor do Sul do País fosse capaz de produzir um livro vendável e 
ignorava pedidos de centenas de livrarias de todas as partes do país.

A obra literária "possui um histórico de venda expressiva até hoje", segundo informações obtidas do Departamento Comercial da Companhia da Letras, editora que comercializa os livros do escritor. Portanto, Olhai os Lírios do Campo se mantém como o livro mais vendido de Erico Verissimo.

Certa vez um jornalista me perguntou no Rio, durante uma entrevista coletiva, se eu não teria sido influenciado por A Cidadela, de Cronin, quando escrevi Olhai os Lírios do Campo. Respondi que não havia lido esse livro, mas que estava disposto a admitir a possibilidade de ter sido de certo modo induzido a escrever uma estória de médicos por estarem em voga naquela época dos livros desse gênero. Hoje pensando melhor, verifico que na verdade a semente desse meu romance jazia adormecida dentro de mim desde os tempos de ginásio, quando muitas vezes pensei em fazer um dia meu avô Franklin Verissimo personagem central de um romance que deveria chamar-se $\mathrm{O}$ Médico. (VERISSIMO, 1974, p.268).

Nessa fase da carreira, o autor começava a ganhar direitos autorais mais altos, como também recebia grande quantidade de cartas de leitores que haviam lido o romance. Conforme relata Erico, o público encontrava nele inspiração, consolo ou estímulo. Os leitores pediam conselhos ou iam até o seu escritório para expor seus problemas e queixas, na esperança de que Verissimo pudesse resolver dificuldades de "ordem sentimental, moral ou financeira". A editora logo se consagra com respeitáveis publicações após o sucesso da obra.

Dois anos após o lançamento, Olhai dos Lírios do Campo continuava com edições esgotadas, mas Erico achava tamanho êxito um perigo quando na sua receita encontrava-se justamente aquilo que o público quer consumir. $O$ autor comenta a aceitação da crítica menos sofisticada, esquecendo os dissabores. Era o início da Segunda Guerra Mundial com a invasão nazista na França, a humanidade pedia por ficção de compreensível consumo como válvula de escape para os males do mundo.

Ao analisar as imparcialidades de seus romances anteriores, o escritor percebe o quão pouco, na sua essência e existência, eles tinham a ver com o Rio Grande do Sul. De acordo com o relato, tendiam para um "cosmopolitismo sofisticado", que levava Verissimo a descrever a "provincianíssima" Porto Alegre de 1934 como uma "metrópole tentacular e turbulenta que recendia à gasolina queimada e asfalto". Em Olhai os Lírios do Campo Erico Verissimo é praticamente premonitório ao criar a personagem Felipe Lobo, arquiteto, que está construindo um prédio de 30 andares, o qual, na realidade, foi construído vinte e cinco anos após a publicação do romance.

Embora fosse admirador de obras isoladas de escritores como Simões Lopes Neto, Darcy Azambuja, Ciro Martins e Vargas Neto, o autor destaca não gostar do gênero regional literário. Apesar de sua família ser da região da Campanha, detestava a vida rural, não andava a cavalo e desconhecia o jargão gauchesco. Estava convencido da importância de desconstruir e narrar episódios da sua cultura. Passado o êxito de seu primeiro bestseller, já pensava em escrever $O$ Continente, como processo de oposição ao cenário urbano de suas obras anteriores. Mas seu próximo romance seria $O$ Resto é Silêncio, ainda voltado para o cenário urbano, mas anunciado, ao final, o empreendimento da trilogia O Tempo e o Vento.

\section{Escritor verbaliza o cinema}

Solo de Clarineta revela que o interesse de Erico Verissimo por cinema começou muito cedo, como ele mesmo relata:

Com uma lanterna mágica, aparelho primitivo de projeção, dotado de uma lente de aumento através da qual passava uma luz de uma lâmpada de querosene, projetando numa parede branca ou em telas improvisadas com toalhas ou lençóis, histórias em quadrinhos. (VERISSIMO, 1974, p.103 e 104).

Aos sete anos, Verissimo já era frequentador assíduo do único cinema de sua cidade natal, Cruz Alta, interior do Rio Grande do Sul. A sala de projeção era administrada pelo senhor Lacombe. O escritor conta esse episódio ao lembrar-se que não pagava a entrada, porque o dono do cinema era amigo de sua família. Aos oito anos, ele ganhou um projetor no qual passava os filmes de celuloide, em que as figuras se moviam como as do "cinema de verdade" (p. 104), 
num ritmo conseguido pelo movimento de quem manejava a manivela, regulando o carretel de filme. Como rememora o escritor, a fita mais popular entre seus amigos chamava-se Dança das Serpentinas. Nessa obra havia movimentos de dança capturados pelo cinematógrafo dos Irmãos Lumiére, também encantados com a performance da dançarina francesa Loie Fuller. Os pioneiros do cinema foram considerados revolucionários por esse feito e puderam filmar a bailarina em diversas oportunidades.

Erico tinha doze anos no início da Primeira Guerra Mundial. O cinema italiano e o francês eram os mais requisitados produtos culturais na América Latina, e também no resto do mundo. Nessa descoberta do cinema, Verissimo relembra as atrizes italianas Leda Gys, Pina Menichelli, Lydia Borelli, Lydia Quaranta e Francesca Bertini, esta uma popular estrela internacional da época. Quanto aos atores, ele admirava Emílio Ghione e Alberto Capozzi, os quais compara com Humphrey Bogart, ator americano que atuou no clássico Casablanca (1942). Ele refere também Gustavo Serena, Alberto Collo e Amleto Novelli.

Verissimo traz de volta à memória um dos diálogos muito comuns entre seus amigos: "Que tal é a fita de hoje no Biógrafo? - Resposta pronta: "Não presta. É de amor". (1974, p.105).Nessa época de menino, Erico ainda não pensava em ser um romancista, preferia as películas de guerra, as aventuras dos seriados. Ele conta que, entre seus amigos, existia ódio aos filmes de amor "por causa da lentidão de suas cenas" e dos "diálogos intermináveis"(id.). Ele exemplifica tal opinião com o filme italiano A Dama das Camélias, adaptação de livro do escritor francês Alexandre Dumas Filho, de cunho autobiográfico. Assim como em Olhai os Lírios do Campo, o mote do romance está na crise existencial do personagem masculino e a narrativa se desenvolve dentro de uma história de amor. O protagonista encontra em uma pessoa a estabilidade deque necessitava e a perde. O preconceito social também subjaz aos conflitos da obra de Dumas, da mesma forma que em Verissimo. A mesma questão se repete em outro filme que impressionou o autor:

...Os Miseráveis, filme feito na França, ${ }^{4}$ baseado no romance de Victor Hugo, não só me comoveu como despertou também minha indignação. Ao sair do cinema, depois de ver a odisseia do pobre Jean Valjean, fiz este comentário: 'Quem rouba um pão para matar a fome vai para cadeia como ladrão. Isso não está direito!'. Odiei Javert, o cruel policial. Creio que essa foi a primeira manifestação de minha futura atitude com relação a problemas de justiça social. (VERISSIMO, 1974, p. 107).

O autor elege Ingmar Bergmano melhor cineasta da década de 1950 em diante. O diretor sueco era prezado na época como autor de filmes cerebrais, "preenchidos pelos produtos de uma companhia cinematográfica dinamarquesa, a Nordisk, cujo marca era um urso branco em cima do globo terrestre" (1974, p. 107). Segundo conta o escritor, foi essa empresa que lançou a atriz Asta Nielsen internacionalmente, "espécie de antecessora da Greta Garbo". Na companhia também trabalhou o galã Waldemar Psilander. De acordo com a constatação de Verissimo, depois que se deflagrou a Primeira Guerra Mundial, os filmes italianos e franceses começaram a escassear e a ser substituídos por películas feitas nos Estados Unidos. Os filmes americanos conquistaram o público com facilidade pela rapidez de suas cenas, pelas suas novidades em matéria de mobilidade da câmera cinematográfica. $\mathrm{O}$ autor ressalta que não se tratava mais de "teatro filmado", e que os enredos eram novelescos.

De uma superprodução americana que 0 escritor narra ter visto na década de 1910, o que o intrigou foi uma guerra em que se confrontavam dois exércitos, um com uniforme escuro e o outro com fardamento claro. Tudo indicava que pertenciam ambos ao mesmo país, mas confundiam o jovem espectador. Chamava-se "cretinamente" de Guerra de Covardia e Heroísmo. Anos mais tarde ficou sabendo que se tratava do famoso clássico do cinema

\footnotetext{
${ }^{4}$ Provavelmente a versão dirigida por Albert Capellani, com Henry Krauss, Henri Étiévant, Léon Bernard, Maria Ventura em 1912.
} 
americano The Birthof a Nation (direção David W. Griffith, 1915) ${ }^{5}$.

O escritor menciona outras "fábricas de filmes nos Estados Unidos": Biograph, Vitagraph, Realart, Keystone. De acordo com suas memórias, surgia nessa época um novo tipo de heroína, a mulher esportiva, "portátil". Passava a existir outro tipo de protagonista masculino, o caubói, que sempre derrotava o índio no final da história, porque os oponentes de pele vermelha eram considerados perversos e traiçoeiros nos primeiros anos da história do cinema norte-americano.

Verissimo relata que os heróis dos seriados tinham perfis de atleta, joviais, acrobatas. George Walsh era considerado o mais notável do período. 0 torso desses personagens estava sempre nu e eles montavam em cavalos, derrubavam os adversários desarmados. É nesses seriados que a mulher aparece pela primeira vez em luta corporal com o homem.

O escritor reporta a superprodução Os Mistérios de Nova lorque. A obra fazia parte de uma safra considerada "folhetins cinematográficos" ou "cinenovelas", filmes em série exibidos com enorme sucesso em todo o mundo, popularizando e praticamente criando o gênero policial. Esse tipo de série cinematográfica foi muito estimulado pela imprensa; propagandas nos jornais eram publicadas nos meses ou semanas anteriores da exibição da série. Além disso,

...havia ainda as doidas comédias de Mack
Sennett com seus policiais grotescos e
principalmente suas sedutoras banhistas. E
também Harold Lloyd, com seus óculos de
aros de tartaruga, subindo como uma mosca
pelas fachadas dos arranha-céus. Na alta
comédia e no drama, tínhamos Thomas
Meigham, Wallace Reid, William Farnum,
Richard Brathlmess... Nos filmes cômicos,
Buster Keaton, Harry Langdon, Chico Bóia... E
um dia conhecemos Carlitos! (VERISSIMO,
1974, p. 110).

\section{Fim da teatralização}

Considerando essa passagem da teatralização no cinema para o drama policialesco, é útil recorrermos à reflexão de Christian Metz sobre o

\footnotetext{
${ }^{5}$ Um modelo do cinema mudo, narra os acontecimentos mais importantes da criação dos Estados Unidos, a guerra civil no país e o assassinato do presidente Abraham Lincoln.
}

espetáculo cinematográfico e sua forte impressão de realidade, pois "o espetáculo teatral não consegue ser uma reprodução convincente da vida porque o próprio espetáculo faz parte da vida, e de modo muito visível; há intervalos, o ritual social, o espaço real do palco, a presença real do ator" (p. 25, 1972).

Para o teórico francês, o peso disso tudo é demais para que a ficção desenvolvida pela peça seja percebida como real; a cenografia, por exemplo, não tem o efeito de criar um universo diegético, não passa de uma convenção dentro do próprio mundo real. Nesse contexto, podemos acrescer os filmes das décadas de 1930 e 1940, dentre os quais a obra Miradlos Lírios del Campo faz parte, e que exibem resquícios da teatralização em suas cenas.

Verissimo aborda posteriormente os dramas do cinema dos Estados Unidos. Segundo o escritor, tendiam a mostrar a "vida americana pasteurizada", "um país ideal, paradigma de justiça, pureza, progresso material, moral e espírito cristão". A palavra de Deus encontrava-se nas relações, nas atuações de personagens da literatura ou do cinema. Os filmes que saíam fora desse paradigma moral eram boicotados por boa parte do público. A situação se tornou consideravelmente delicada, pois mais tarde os estúdios de Hollywood, que desde 1918 se transformara na Meca do cinema mundial, tiveram de criar uma organização, mantida pelas próprias companhias cinematográficas, para exercer uma espécie de autocensura em seus produtos. Novos códigos foram criados na política do cinema. A distância do galã em relação à heroína, no momento em que se beijavam, por exemplo, era determinada com rigidez.

Conforme relato do escritor Erico Verissimo, os beijos eram cronometrados. O desejado contraste entre grupos sociais e raciais também foram impostos. No caso dos filmes americanos, os bodesexpiatórios foram os mexicanos. Havia ainda os negros, que se dividiam em dois grupos: os revoltados e os humildes, com fidelidade canina aos brancos.

\section{A transposição das memórias}


Com uma intercalação na linha do tempo na autobiografia, relembrando a época de estudante, as cenas contadas, sentado à sombra de uma árvore de ameixa do Japão, segundo a voz do escritor, tratavase de um "marco do tempo de infância e uma entidade importante da sua mitologia particular" (1974, p.55).

Em outra passagem do livro revive também a "sociedade de aparência", que pode ser vista tanto nas páginas escritas por Erico, como em sua preocupação pessoal, como fica claro em suas memórias quando discute qual roupa a ser usada na escola da capital.

Nos meus tempos de Cruzeiro do Sul, uma das fontes do complexo de inferioridade que me perturbava, eram minhas roupas. A fatiota cinzenta domingueira era obra do pior alfaiate de Cruz Alta, que devia ser um dos piores do mundo. (VERISSIMO, 1974, p.126).

Ao considerar um dos aspectos sociais da época, de Olhai os Lírios do Campo destacamos o quase encontro de Eugenio com o pai humilde quando está com seus colegas ricos, em que ficam explícitos classificação da sociedade, seus valores e a questão de poder. O fato revela uma característica latino-americana, de uma significativa transformação coletiva do período, pois novos sentidos do capitalismo tornam-se evidentes em decorrência do crescimento urbano das capitais e novos costumes.

\section{Composição pré-cinematográfica}

Quando Erico Verissimo faleceu, o segundo volume de suas memórias, Solo de Clarineta, estava em plena fase de elaboração. As primeiras páginas, compreendidas pelos capítulos I, II, III e IV, estavam impressas e revisadas pelo autor. A Editora Globo elaborou o plano de publicação, acreditando na importância da autobiografia para os estudiosos da literatura que pretendessem elucidar sua obra.

Nos relatos minuciosos do volume, é possível viajar por quase toda a América Latina, acompanhar sua estada em Washington, na União PanAmericana, conhecer lugares em Portugal, Espanha. O seguinte parágrafo em flashback, recurso literário utilizado para transportar o leitor no tempo e espaço, dá uma ideia do modo de composição do texto:

"... o jovem continua a falar, mas a ideia 'igreja submersa' me faz pensar imediatamente em La Cathédrale Engloutie, de Debussy, e eu passo a ouvir com a memória, num disco de 78 rotações, a sugestiva melodia, contra um fundo feito dum estralar de pipocas. Por alguns segundos não estou mais em Coimbra, em 1959, mas em Cruz Alta, em 1926, tentando compreender Debussy". (VERISSIMO, p. 132, 1976).

Podemos comparar esse trecho em primeira pessoa, em escala micrométrica, à complexidade do flashback de Olhai os Lírios do Campo, no qual são utilizados blocos de textos em tempos diferentes intercalados em toda a extensão da obra. O recurso transporta o leitor ora para infância infeliz de Eugênio em decorrência da pobreza do pai alfaiate e devedor do aluguel; ora para dentro do carro no qual Eugenio está descendo a Serra, em direção ao hospital de Porto Alegre onde Olivia está morrendo. Mas não são só estes episódios que trabalha em flashback, a história possui uma justaposição textual em diversos momentos do trajeto da viagem de Eugenio. Podemos dizer que as cartas de Olivia, da segunda parte do livro, também fazem remissões a episódios do passado e a narrativa se desenvolve como se os trechos de dois tempos dependessem um do outro.

Metz (1972) interpreta a história da literatura e da pintura para um levantamento global; "não são demais para fornecer exemplos de montagem antes da palavra". O teórico menciona o fanatismo da montagem das coletâneas russas; mas pondera ao concluir que Dickens, Leonardo da Vinci ou outros já haviam aproximado dois temas, duas ideias, duas cores, para que Eisenstein pudesse proclamar 0 advento da montagem: a justaposição mais obviamente pictórica, o efeito de composição mais tradicional em literatura tornam-se, para ele, profeticamente pré-cinematográficas.

\section{0 plano no aporte de Lotman}


Para o teórico russo, o plano não é somente uma medida da representação, mas a relação desta com o quadro. De acordo com sua análise, o grande plano e o pequeno plano não existem só no cinema. Encontra-se nitidamente na narração literária, quando o lugar ou a atenção se combinam com fenômenos cujas características quantitativas são diversas.

Assim, por exemplo, se os segmentos de um texto que se seguem se preenchem de um conteúdo, distinto do ponto de vista quantitativo: de um número diverso de personagens, do todo e das partes, da descrição de objetos de grande e de pequena dimensão; se, num romance qualquer, se descrevem num capítulo os acontecimentos do dia e num outro de dezenas de anos, podemos falar igualmente de uma diferença de plano. (LOTMAN, 1978, p. 421).

A reflexão de Lotman, quando discute as nuances da narrativa romântica, reflete os pontos de vista e a veracidade dos sentimentos colocados no centro único imóvel da narração, a personalidade do autor. Conforme sua análise, a unificação do ponto de vista torna-se sinônima do subjetivismo romântico. O pioneirismo, segundo ele, encontra-se na literatura russa, através do livro Eugênio Oneguine (1932), uma personagem de ficção. Subjetivamente, isso foi entendido como movimento do poema romântico para um gênero narrativo, o romance.

\section{Considerações finais}

Como vimos, nada mais cinematográfico do que esta montagem de tramas que Erico Verissimo foi construindo ao longo de sua trajetória como escritor. As personagens, inspiradas na vida do autor ou não, propõem refletira criação e a maneira de escrever, sinalizando um traço importante e até determinante das obras analisadas.

Buscando referências cinematográficas e memórias do livro Olhai os Lírios do Campo em Solo de Clarineta enfatizamos trechos que concorrem para o entendimento do processo de criação do romance. Nessa linha de pensamento, descobrimos nele as nuances da montagem, sua origem em outras artes e as semelhanças estruturais entre literatura e cinema. Entendemos que essa organização para contar histórias populares segue métodos narrativos que tem o objetivo de satisfazer uma demanda de mercado. Subjaz a essa estrutura e a esse método uma intenção de controle e orientação do discurso.

Elencamos informações da obra autobiográfica que remetiam ao best-seller de Verissimo de forma direta ou indireta, pois as variantes cinematográficas também colaboram no entendimento do formato livro e seu resultado. Nesse sentido, o cinema desempenha um papel de referência no reordenamento da orientação e da compreensão da sociedade contemporânea. O diálogo entre dois tipos de obras do mesmo autor e a imersão em referências da "sétima arte" pretende expandir o debate entre literatura e cinema, montagem e adaptação. A relevância literária da obra Olhai os Lírios do Campo pode ser verificada tanto no texto autobiográfico quanto em seus próprios resultados culturais, sociais e, sobretudo, históricos. Com o aporte autobiográfico, comparamos e analisamos a habilidade do romancista como narrador de episódios de vida, que são os que mais falam aos leitores.

\section{Referencias}

LOTMAN, luri. A estrutura do texto artístico. Tradução de M.C.V. Raposo e A. Raposo. Lisboa: Estampa, 1978.

METZ, C. A significação no cinema. São Paulo: Perspectiva, 1972.

SEVERO, José Augusto. Trinta anos de um romance. Correio do Povo, Porto Alegre, p. 6, 29 jun. 1968. Caderno de Sábado. (03c 0038-1968).

VERISSIMO, Erico. Olhai os lírios do campo. São Paulo: Companhia das Letras, 2005.

VERISSIMO, Erico. Solo de clarineta: memórias. Porto Alegre: Editora Globo, 1974. v.1.

VERISSIMO, Erico. Solo de Clarineta. Porto Alegre: Editora Globo, 1976. v.2. 


\section{COMO CITAR ESSE ARTIGO}

DOS SANTOS, Márcio Soares. Os filmes verbais de Erico Verissimo: uma abordagem cinematográfica e literária de Olhai os Lírios do Campo em Solo de Clarineta. Signo, Santa Cruz do Sul, v. 44, n. 81, dez. 2019. ISSN 1982-2014. Disponível em: <https://online.unisc.br/seer/index.php/signo/article/view/13733>. Acesso em: . doi: https://doi.org/10.17058/signo.v44i81.13733. 